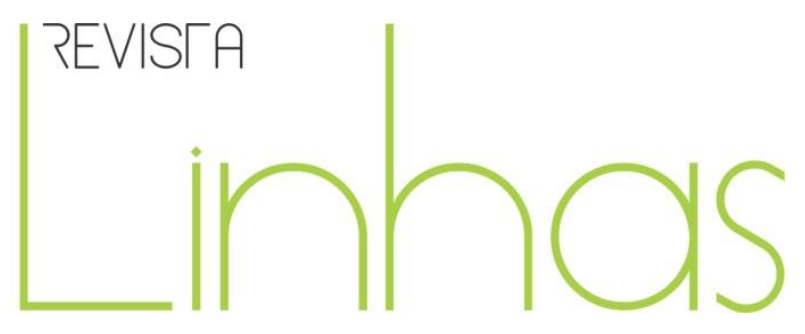

\title{
Resenha do livro "Trilhas, roteiros e legendas de uma cidade chamada Duque de Caxias: memórias e representações de Francisco Barboza Leite (1950-1990)"
}

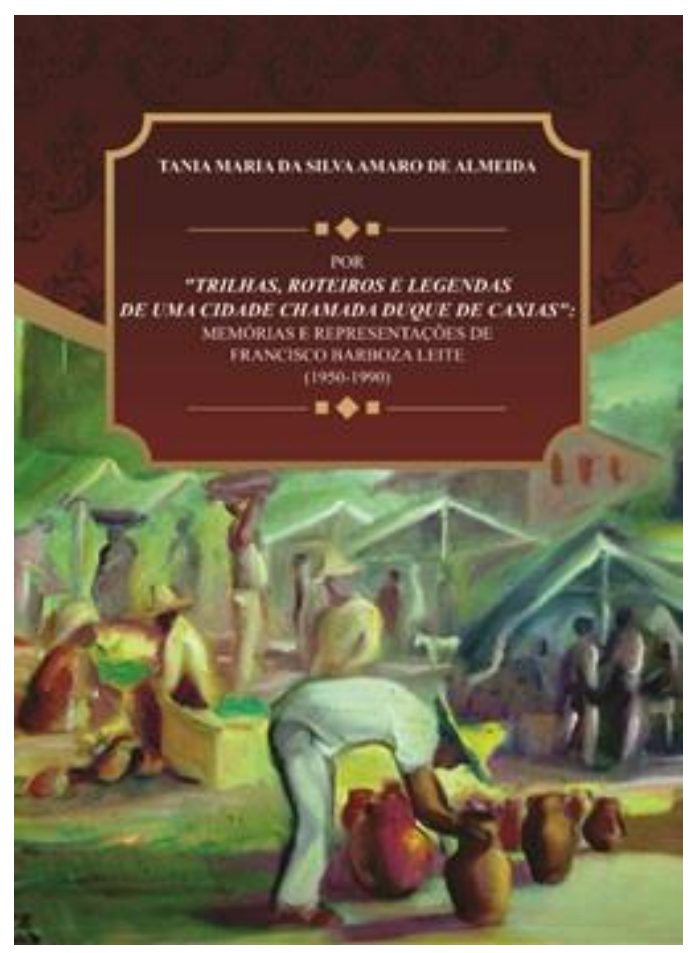

ALMEIDA, Tania Maria da Silva Amaro de. Trilhas, roteiros e legendas de uma cidade chamada Duque de Caxias: memórias e representações de Francisco Barboza Leite (19501990). Duque de Caxias: ASAMIH, 2019. 356p.

\section{Eliana Santos da Silva Laurentino}

Secretaria Estadual de Educação - Rio de Janeiro/RJ - Brasil

laurentinoeliana@gmail.com

\section{Para citar esta resenha:}

LAURENTINO, Eliana Santos da Silva. Resenha do livro "Trilhas, roteiros e legendas de uma cidade chamada Duque de Caxias: memórias e representações de Francisco Barboza Leite (1950-1990)". Revista Linhas.

Florianópolis, v. 22, n. 50, p. 351-357, set./dez. 2021. 
Vou falar de uma cidade

da Baixada Fluminense

que ganhou notoriedade que ao meu sentir não convence

- é preciso que se repense o que ela foi dito

em tanto papel mal escrito que a imprensa divulgava

e, de tal modo criava

a noção falsa de um mito

A cidade é muito nova mas cresceu muito depressa

digo e ofereço a prova que é o que me interessa para quem o valor meça de uma terra em expansão

formada sem previsão

guiada só pelo senso de um proveito assaz imenso fruto espontâneo do chão.

(LEITE, 1975)

Duque de Caxias, retratado no cordel de Francisco Barboza Leite (1975), é considerado um dos principais municípios que compõem a região metropolitana do Estado do Rio de Janeiro, e que, durante muito tempo, "ganhou notoriedade", devido à imagem de violência presente nas manchetes de jornais. No entanto, para muitos, como no caso do poeta, a cidade possui outras características, muitas qualidades. O município de Duque de Caxias se constituiu administrativamente desvinculado de Nova Iguaçu em 1943, quando o então $8^{\circ}$ Distrito de Nova Iguaçu, sob a denominação de Caxias, teria adquirido autonomia, com São João de Meriti, Xerém e Estrela, e se tornado o município de Duque de Caxias. Particularmente, nos anos 1950 e 1960, a partir da expansão demográfica da região metropolitana do município do Rio de Janeiro, foi crescente o volume de ocupações de terras e de venda de loteamentos na Baixada Fluminense ${ }^{1}$. Tais acontecimentos renderam registros na imprensa sobre as lutas por terra, com destaque para as ações de violência no

\footnotetext{
${ }^{1}$ A Baixada Fluminense é formada por um conjunto de municípios que compõem a região metropolitana do Estado do Rio de Janeiro. Para Manoel Ricardo Simões (2006), não existe uma definição precisa da Baixada Fluminense, com limites e municípios específicos, o que pode variar conforme os interesses do pesquisador. Entretanto, parece unânime que Duque de Caxias e Nova Iguaçu sejam "o núcleo duro" da região, e que também sejam considerados como parte desse território os municípios "satélites": São João de Meriti, Nilópolis, Belford Roxo, Queimados, Mesquita e Japeri.
} 
território. Tanto o cordel de Barboza Leite (1975) quanto a historiografia sobre a Baixada Fluminense se inserem no esforço de pesquisar, escrever, registrar e valorizar a memória e a história na região, ao proporem outras leituras ou novas problematizações sobre o seu passado.

Em Trilhas, roteiros e legendas de uma cidade chamada Duque de Caxias: memórias e representações de Francisco Barboza Leite (1950-1990), resultado da tese de doutorado realizada por Tânia Amaro (2017), defendida no Programa de Humanidades, Cultura e Artes da UNIGRANRIO, a proposta é acompanhar, por meio das representações literárias de Francisco Barboza Leite, as transformações sociais no município e as concepções sobre uma Duque de Caxias na qual o artista viveu e atuou em diferentes espaços.

Tânia Amaro é diretora do Instituto Histórico da Câmara Municipal de Duque de Caxias, desde 2002. O instituto foi criado pelo legislativo da cidade, em 1971, com sua sede dentro da Câmara Municipal e, ao longo dos anos, o espaço se tornou uma referência para os pesquisadores que desejam se debruçar sobre a história da Baixada Fluminense. Imersa nesse universo, Tânia Amaro desenvolveu seu mestrado e seu doutorado em uma perspectiva de olhar a relação entre a História e a Literatura.

Sua dissertação, intitulada Olhares sobre uma cidade refletida: memória e representações de Santos Lemos sobre Duque de Caxias (1950-1990), foi defendida em 2012, pelo Programa de Letras e Ciências Humanas da Universidade do Grande Rio (UNIGRANRIO), unidade de Duque de Caxias. Em 2014, a dissertação foi publicada pela Associação de Amigos do Instituto Histórico de Duque de Caxias (ASAMIH). A tese, publicada no ano de 2019, reforça os investimentos da autora, do instituto e dos membros da ASAMIH de promover um crescimento e a valorização das pesquisas sobre a História Local e Regional.

O livro de Amaro reconhece que outras perspectivas teóricas e recortes temáticos se debruçaram sobre a história da cidade, e reforça que sua abordagem considera a análise da poética e literatura de Francisco Barboza Leite para apresentar as outras representações sobre Duque de Caxias. A autora informa que o ícone escolhido possui uma trajetória intensa e suas experiências no Nordeste se refletem em suas práticas em Duque de Caxias. Além de atuar como escritor, Barboza Leite (1920-1997) também era cenógrafo, 
artista plástico, poeta, compositor, escreveu muitos livros de poesia, contos, crônicas, cordéis e foi idealizador de jornais locais, como o Grupo e Tópico.

Sua multiplicidade de talentos se refletiu em muitas experiências e na atuação direta em diversos espaços. O livro de Amaro analisa o impacto dessas diferentes atuações e como foram representadas nas produções poéticas do artista. Desde o momento em que foi apresentado à cidade de Duque de Caxias, em 1947, por seu amigo Solano Trindade, outro ícone da região, Barboza Leite ocupou cargos significativos. Ele foi funcionário do Instituto Brasileiro de Geografia e Estatística (IBGE), membro do corpo docente da Universidade Federal do Rio de Janeiro e professor do Curso Normal do Colégio Santo Antônio. Além disso, foi coordenador da Escolinha de Arte da Fundação Álvaro Alberto, a antiga Escola Regional de Meriti, e também colaborou com a Orquestra Sinfônica de Duque de Caxias e compôs a canção Exaltação à cidade de Duque de Caxias, que se tornou o hino oficial da cidade.

Por meio da diversidade de atuação de Barboza Leite, Tânia Amaro ressalta o envolvimento do artista com a cidade, que, de acordo com sua análise, é evidenciada na homenagem realizada a ele, por meio da Lei $n^{\circ}$. 1.926/2005, que reconhece o dia 20 de março, data de nascimento do artista, como o Dia Municipal da Cultura. Dessa forma, o trabalho de Tânia Amaro se destaca pela leitura da cidade, a partir das fontes literárias, com uma proposta de apresentar uma análise na perspectiva da História Cultural, considerando as representações de quem viveu em uma Duque de Caxias, a partir do contexto da década de 1950, marcada pelo crescente fluxo migratório e por investimentos na industrialização. Assim, as marcas das experiências do cearense, em um território que recebeu um grande fluxo nordestino, somaram-se aos discursos de progresso do contexto.

Amaro considera que Leite, que tinha dimensão do crescimento desordenado da cidade e das angústias cotidianas (expressa, por exemplo, no cordel apresentado na epígrafe desta resenha), realizou uma abordagem com um olhar mais voltado para a dimensão de luta trabalhadora, dos valores pátrios e da busca pelo progresso, o que seria uma face da representação esperançosa presente nas produções sobre a história local.

O livro de Tânia Amaro nos permite acompanhar que, apesar do artista ter chegado em uma Duque de Caxias carente de infraestrutura adequada, sem calçamento, 
canalização de água e esgoto, para Barboza Leite, a cidadania seria construída também a partir das questões culturais. Amaro reforça essa perspectiva ao apresentar uma fala de Barboza Leite em um concurso de poesias, realizado no Instituto de Educação Governador Roberto Silveira, da qual destaco um trecho: “fazer poesia é libertar-se, construindo; é cansar-se, mas sem desistir. E é, sobretudo, viver muitas vezes até que, pela leitura de seus poemas, o poeta mostre novos caminhos à humanidade" (LEITE, 1985 apud AMARO, 2019, p. 202).

Dessa forma, o livro de Amaro, organizado em quatro capítulos, se propõe a apresentar, por meio de uma análise do discurso do artista, expresso nas diversas representações literárias, como em desenhos, poemas, cordéis e entrevistas, a cidade de Duque de Caxias. Na relação entre História e Literatura, a autora apresenta o protagonismo de quem viveu e registrou o cotidiano na e da cidade.

O primeiro capítulo, “A cidade em narrativas”, é um esforço de pontuar os caminhos teóricos da autora, ao destacar como compreende os significados do trabalho de Barboza Leite a partir da relação entre memória e história, bem como de entender o papel do discurso e das leituras sobre a cidade. Nesse capítulo, é possível se perguntar se Amaro considera que Barboza Leite é observado como um símbolo de Duque de Caxias ou se foi ele quem elegeu Duque de Caxias como símbolo, já que a autora nos apresenta muito dos significados da escrita da cidade para o artista, e como o autor se tornou um símbolo, por meio do hino da cidade e de outros elementos de homenagem.

Em “Memória e representações de uma cidade: a constituição do município de Duque de Caxias", a proposta é mergulhar na historicidade da cidade. Neste capítulo, está presente muito da atuação da historiadora Amaro, que aplica e recupera sua experiência com estudos e pesquisas sobre a Baixada Fluminense. Ela aborda os impactos da ocupação colonial da região, o papel dos caminhos e das estradas no território atualmente conhecido como Baixada Fluminense, e a relação com as demandas da cidade do Rio de Janeiro ao longo dos anos. Além disso, é possível identificar os processos de ocupação da cidade, a ampliação dos meios de transportes, especialmente com as ferrovias, e a atuação de diferentes grupos e interesses para o crescimento e o desenvolvimento de Duque de Caxias. Assim, a autora apresenta o cenário de chegada de Barboza Leite, ao evidenciar as transformações materiais e sociais da cidade. 
Já no terceiro capítulo, “A trajetória do pintor-poeta", é abordada a origem nordestina do artista, sua trajetória e como suas obras são carregadas de marcas de sua infância. Nascido em Uruoca, no Ceará, e filho de artesão, Barboza Leite viveu diferentes experiências. Foi para a capital, Fortaleza, teve passagem por Recife e pelo Rio de Janeiro, até se fixar em Duque de Caxias. Assim, o capítulo se propõe a apresentar a historicidade do artista pelas regiões em que passou e como suas obras dialogam com esses espaços, expressos nos poemas, nos cordéis e na pintura. Destaca-se, no capítulo, a decisão de Barboza Leite de ficar em Duque de Caxias, sua relação com Solano Trindade, outro ícone da cidade, e a sensibilidade do artista diante dos contextos vividos.

Já o último capítulo, "A literatura do artista da palavra”, aborda o contexto da cidade, entre os anos 1950 e 1990, por meio da literatura do autor. Tania Amaro fala das representações de uma Duque de Caxias presentes nas produções literárias de Leite, e de como as obras, mesmo ao exporem as misérias da humanidade, têm um olhar de esperança. Isso se confirma em diálogo com outros interlocutores que escreveram sobre o artista, como Rogério Torres. Para ele, que atuou diretamente com Leite e é um grande admirador das produções do artista, temas como "os retirantes, a seca, a guerra, os manifestos artísticos, os movimentos sinuosos da política, os jovens, as ruas e suas encruzilhadas [são] matéria-prima para seu universo de artista e poesia, que tenta elevar o homem à altura das estrelas" (TORRES, 1983 apud AMARO, 2019, p. 266).

O capítulo enfatiza, ainda, os registros do artista sobre as memórias do cotidiano e as interações com o espaço. Nas análises dos trabalhos sobre a feira de Duque de Caxias, reconhecida como uma marca identitária da cidade para o artista, são representadas as ações dos migrantes na construção do munícipio. Além da feira, os escritos Trilhas, roteiros e legendas de uma cidade chamada Duque de Caxias, escolhidos por Amaro para nomear o livro, reforçam que a proposta de Leite era valorizar a cidade e não a criticar.

O livro Trilhas, roteiros e legendas de uma cidade chamada Duque de Caxias: memórias e representações de Francisco Barboza Leite (1950-1990), de Tania Amaro, expressa a potencialidade de leituras sobre a cidade. Por meio da relação entre História e Literatura, a autora nos permite acompanhar como o artista, que possuía múltiplos talentos e que atuou em diferentes órgãos, expressou suas representações sobre Duque de Caxias. 
LEITE, Francisco Barboza. A verdadeira história da cidade de Duque de Caxias. Cordel. In: ALMEIDA, Tania Amaro. Trilhas, roteiros e legendas de uma cidade chamada Duque de Caxias: memórias e representações de Francisco Barboza Leite (1950-1990). Duque de Caxias: ASAMIH, 2019, p. 119.

SIMÕES, M. R. A cidade estilhaçada. Reestruturação econômica e emancipações municipais na Baixada Fluminense. Mesquita: Entorno, 2006. 